\title{
Caracterização de indivíduos da Fronteira Oeste/RS (Brasil) que pos- suem o hábito de tomar chimarrão em temperatura elevada
}

\author{
Characterization of people from Western Rio Grande do Sul (Brazil) which drink \\ "chimarrão" at high temperature
}

\author{
Ana Paula Fleig Saidelles ${ }^{1}$, Rosane Kirchner ${ }^{2}$, Nara Zamberlan dos Santos ${ }^{3}$, \\ Eniva Miladi Fernandes Stumm ${ }^{4}$, Liange Reck ${ }^{5}$, Rayara de Sene Machado ${ }^{6}$ \\ ${ }^{1}$ Doutora, Universidade Federal do Pampa, Brasil \\ ${ }^{2}$ Doutora, Universidade Federal de Santa Maria, Frederico Westphalen, Brasil \\ ${ }^{3}$ Doutora, Universidade Federal do Pampa, Brasil \\ ${ }^{4}$ Doutora, Universidade Regional do noroeste do Estado do Rio Grande do Sul, Ijuí, Brasil \\ ${ }^{5}$ Mestra, Universidade Federal de Santa Maria, Santa Maria, Brasil \\ ${ }^{6}$ Gestora Ambiental, Universidade Federal do Pampa, Brasil
}

\begin{abstract}
Resumo
O "chimarrão" é uma bebida servida a quente de erva-mate (Ilex paraguariensis) que além de fazer parte da cultura regional, possui valor comercial para os estados do sul do Brasil. A presente pesquisa teve por objetivo caracterizar indivíduos que residem em um município da fronteira oeste do estado do Rio Grande do Sul, que possuem o hábito de tomar chimarrão, bem como analisar suas concepções referentes ao uso e a temperatura da água. Foi aplicado um questionário para 205 indivíduos, entre agosto e dezembro de 2008 em um município da fronteira oeste/RS, contendo características sociodemográficas dos pesquisados, benefícios, maleficios e temperatura de consumo da bebida. As temperaturas foram medidas utilizando um termômetro na água da cuia e da térmica. $O$ perfil dos usuários foi: 51,7\% mulheres, 48,5\% casados, 48,76\% com idade entre 20 e 40 anos, 71,2\% com no mínimo o ensino médio completo. Para a maioria, o início do consumo do chimarrão ocorreu entre 10 e 20 anos. O consumo para 74,6\% dos entrevistados é de pelo menos de uma vez ao dia, variando entre 8 cuias até uma garrafa térmica (um litro), os quais preferem o chimarrão quente e sem açúcar. A simbologia do uso é traduzida por "amizade" e "família". Reconhecem como efeitos benéficos o fato de a bebida ser "diurética" e "facilitar a digestão". A temperatura da água nas garrafas térmicas e nas cuias demonstrou que a maioria dos usuários a utiliza acima de $60^{\circ} \mathrm{C}$, tornando-os vulneráveis a doenças. Os resultados podem desencadear reflexões, discussões e ações da população no sentido de minimizar riscos à saúde dos consumidores de chimarrão.
\end{abstract}

Palavras-chave: Chá, Ingestão de Líquidos, Efeitos Adversos, Saúde Pública.

\begin{abstract}
The "chimarrão" is a drink served hot yerba mate(Ilex paraguariensis) usually is part of the culture and has important commercial value for the southern states of Brazil. The present study aimed to characterize individuals who who lives in an Western city of Rio Grande do Sul, which have the habit of drinking mate, as well as analyzing their conceptions regarding the use and the water temperature. A questionnaire was applied to 205 individuals between August and December 2008 in a city of the western border/RS, raising social/demographic profile of interviewed individuals, as well as information about benefits, harms and temperature of drinking consumption. Temperatures were measured using a thermometer. Their profile was: $51.7 \%$ woman; $48.5 \%$ married; $48.76 \%$ were age between 20 to 40 years; $71.2 \%$ had at least high school education; for the majority, the starting age of "chimarrão" consumption was between 10 and 20 years. The frequency of consumption for $74.6 \%$ of the individuals is at least once a day, ranging from 8 bowls to a thermal bottle (one liter) and they prefer hot "chimarrão" and without sugar. In the interviewed opinions, the symbolism of "chimarrão" consumption can be translated as "friendship" and "family". It is recognized as a beneficial drink by its "diuretic effects" and "digestion improvements". The water temperature in the thermal bottles and bowls have shown that most consumers use it above $60^{\circ} \mathrm{C}$, making them vulnerable to diseases. The results of this study may stimulate reflections, discussions and actions by the population in order to minimize health risks for the "chimarrão" consumers.
\end{abstract}

Keywords:Tea, Drinking, Adverse Effects, Public Health. 


\section{Introdução}

Nos estados do sul do Brasil, a erva-mate (Ilex paraguariensis) ingerida como bebida servida a quente, o chamado "chimarrão", faz parte de uma cultura difundida tanto no meio rural como no urbano. O hábito de tomar chimarrão está presente na América do Sul, principalmente no Rio Grande do Sul, Uruguai e nordeste da Argentina. No Rio Grande do Sul, especificamente, o chimarrão é símbolo de hospitalidade e tradição, sendo oferecido a visitantes, com importante valor comercial (Schneider et al. 2009).

O chimarrão é um hábito e um costume das "autênticas" tradições gaúchas (FREITAS \& SILVEIRA 2004). É considerado uma herança cultural, com influência na formação da identidade do gaúcho e da sua personalidade (Michelin, 2007). Nesse contexto, a popular infusão de erva-mate é consumida em grandes volumes e muitas vezes em temperaturas elevadas, tornando-se um fator de risco para carcinoma epidermoide (BARROS et al, 2000).

Pesquisas comparando indivíduos que ingeriram o chimarrão, em altas temperaturas, e morno a quente mostram que os primeiros apresentaram maior possibilidade de desenvolver câncer de esôfago (ROLON et al., 1995; SEWRAM et al. 2003) . O consumo em grande quantidade (ao redor de 1,8 1/dia) potencializa a ação da lesão, facilitando a ocorrência de câncer (SILVA, 2008) .

Segundo alguns autores (CRADDOK, 1992; DAY \& VARGHESE, 1994), a frequência do câncer de esôfago em humanos apresenta maior incidência em áreas da França, China, Irã, África do Sul e América do Sul. Nesses países, essa doença pode estar associada ao uso de álcool, cigarro, deficiências nutricionais, consumo de bebidas quentes (chás, chimarrão), baixo nível socioeconômico e predisposição genética (CRADDOK, 1992; GAMMON et al., 1997; ALVES et al. 2007)

Essa tradição pode trazer benefícios, tais como absorção de minerais essenciais (por ex. cálcio, magnésio e potássio) e interação social. Por outro lado, poderá trazer danos à saúde, incluindo insônia e câncer do esôfago, entre outros (ERNST, 2007). Existem poucos trabalhos científicos que focalizam os benefícios ou danos provocados à saúde humana (MEDRADO \& MOSELE, 2004). No Brasil, avaliações são realizadas sobre a possibilidade do uso de erva-mate como fonte de ação medicamentosa. Em outros países, há resultados de pesquisas relacionadas a produtos para dietas, vaso-relaxantes, diabetes, antioxidante, inibidor de mutagênicos, entre outros (MEDRADO \& MOSELE, 2004).

Considerando o exposto, buscou-se, com a presente pesquisa, caracterizar indivíduos que residem em um município da fronteira oeste do estado do Rio grande do Sul e que possuem o hábito de tomar chimarrão, bem como analisar suas concepções referentes ao uso e à temperatura da água.

\section{Materiais e métodos}

A pesquisa se caracteriza como transversal, quantitativa e descritiva (BARBETTA, 2007). A coleta de dados foi realizada com moradores de um município da Fronteira Oeste do Rio Grande do Sul, Brasil, que possui uma população de 7.347 .657 habitantes com 16 anos de idade ou mais (Censo Demográfico 2000, IBGE). A amostra compreendeu 205 indivíduos que possuem o hábito de tomar chimarrão, considerando uma margem de erro de 7\% (BARBETTA, 2007).

Foi aplicado um questionário nos meses de agosto a dezembro de 2008, contemplando as seguintes variáveis: idade, gênero, escolaridade, idade de início do consumo de chimarrão, frequência do uso, benefícios, prejuízos à saúde, tipo de erva-mate utilizada e simbologia. Também foi realizada a medição da temperatura das águas na cuia e na garrafa térmica, durante as entrevistas.

O questionário foi aplicado de forma aleatória, em pontos estratégicos da cidade, buscando atingir o maior número de logradouros possível. Para tanto, elencouse os seguintes critérios de seleção dos participantes da pesquisa: possuir idade maior de 16 anos, aceitar participar da pesquisa e estar tomando chimarrão no momento da abordagem pelos pesquisadores.

Foram realizadas aferições da temperatura da água diretamente das cuias e das garrafas térmicas. As medidas das temperaturas foram obtidas pelos pesquisadores utilizando termômetros específicos, desinfetados por processo químico, com padronização de um tempo de 20 segundos (estabilizado para leitura), sendo que nesse período a ponta do termômetro ficava submersa na água existente tanto na cuia quanto na garrafa térmica.

Os dados obtidos foram analisados utilizando técnicas da estatística descritiva, entre elas: média, desvio padrão e coeficiente de variação. Os dados foram analisados com o software SPSS e apresentados em forma de tabelas.

Quanto aos aspectos éticos que envolvem pesquisas com pessoas, todos foram observados, ou seja, os participantes foram informados acerca dos objetivos da pesquisa, e convidados a integrarem-se à população estudada. Aos que aceitaram, assinaram o Termo de Consentimento Livre e Esclarecido, em duas vias, ficando uma em poder das pesquisadoras e a outra com os participantes. Foi-lhes garantido anonimato, liberdade de desistir de participar da pesquisa a qualquer momento e segurança de que os dados obtidos com a pesquisa seriam utilizados exclusivamente para fins científicos e para esta pesquisa. Foram igualmente esclarecidos de que não teriam beneficio financeiro algum por participar.

\section{Resultados e discussão}

Inicialmente, considera-se importante destacar as características da amostra estudada. Evidencia-se semelhança entre a quantidade de homens (51,7\%) e mulheres $(48,3 \%)$, em percentuais aproximados. Praticamente a 
metade deles é casada (48,5\%), a média de idade foi de $39,76 \pm 18,07$ anos, com predomínio da faixa etária de 20 a 40 anos $(48,76 \%)$. Nesse contexto, um estudo realizado na região de Taquara-RS (BARROS et al., 2000), com consumidores de chimarrão, visando verificar hábitos de ingestão e a temperatura do consumo, mostrou que mais da metade $(58,3 \%)$ dos pesquisados era do gênero feminino, com média de idade de 52,08 anos, superior à da amostra em estudo.

Analisando a escolaridade dos indivíduos que integraram essa pesquisa, constatou-se que $71,2 \%$ cursaram o ensino médio completo ou superior incompleto ou completo. Quanto à idade de início do consumo de chimarrão, constatou-se que, na maioria dos pesquisados (77\%), isto ocorreu entre 10 a 20 anos de idade.

Quanto à quantidade, frequência do uso e caracte- rísticas do chimarrão (Tabela 1), observou-se que 74,6\% dos pesquisados relataram ingerir a referida bebida pelo menos uma vez ao dia. Em uma pesquisa de Barros, et al. (2000), das 36 famílias pesquisadas, quanto à frequência do hábito, 35 pessoas responderam que a frequência de uso é diária e somente uma pessoa respondeu que toma chimarrão até três dias por semana. No que tange à quantidade de cuias, 67,9\% consomem mais de 8 e $62 \%$ até uma garrafa térmica (mínimo $1000 \mathrm{ml}$ ou 11 ) de água. Nesse sentido, os consumidores do chimarrão no sul da América ingerem um volume de água superior a 1,5 1/dia (CASTELLSAGUÉ et al., 2000).

Ainda em relação aos dados contidos na Tabela 1, quanto à percepção dos participantes referente à temperatura da água do chimarrão e o tipo da erva-mate, constatou-se que a maioria consome o chimarrão quente

Tabela 1. Quantidade, frequência do uso e características do chimarrão

\begin{tabular}{lcc}
\hline \multicolumn{1}{c}{ Variáveis } & $\mathrm{N}$ & $\%$ \\
\hline $\begin{array}{l}\text { Frequência do consumo de } \\
\text { chimarrão }\end{array}$ & & \\
Diariamente, mais de uma vez ao dia & 90 & 43,9 \\
$\begin{array}{l}\text { Diariamente, uma vez ao dia } \\
\text { Até 3 vezes por semana }\end{array}$ & 63 & 30,7 \\
Raramente & 13 & 18,0 \\
Menos de uma vez por semana & 2 & 6,3 \\
& & \\
Quantidade de cuias & \\
Mai* & & \\
De 8 a 11 cuias & 86 & 44,6 \\
De 4 a 7 cuias & 45 & 23,3 \\
Até 3 cuias & 32 & 16,6 \\
& 30 & 15,5 \\
Quantidade de garrafas térmicas** & & \\
Até uma garrafa & & \\
De 2 a 3 garrafas & 122 & 62,0 \\
De 4 a 5 garrafas & 59 & 29,9 \\
Mais de 6 garrafas & 13 & 6,6 \\
\end{tabular}

$\begin{array}{lcc}\begin{array}{l}\text { Percepções referentes à temperatura } \\ \text { da água* }\end{array} & & \\ \text { Quente } & 151 & 76,3 \\ \text { Morno } & 44 & 22,2 \\ \text { Muito Quente } & 3 & 1,5\end{array}$

\section{Características da erva-mate}

\begin{tabular}{lcc} 
Sem açúcar & 177 & 86,3 \\
Com açúcar & 28 & 13,7 \\
\hline
\end{tabular}

\% válida: * sete entrevistados não responderam; ** oito entrevistados não responderam; *** doze entrevistados não responderam.

Fonte: Dados da pesquisa - 2008. 
(76,3\%) e com erva-mate sem açúcar (86,3\%). Corroborando, Silva (2008, p.09) afirma que "o consumo de mate em altas temperaturas tem sido considerado fator de risco para o desenvolvimento do carcinoma epidermóide de esôfago (CE) na América do Sul".

Os consumidores pesquisados ao serem questionados (Tabela 2) quanto aos benefícios do consumo de chimarrão responderam que é "muito benéfico" por facilitar a digestão $(65,2 \%)$, proporcionar bem-estar e vigor $(35,6 \%)$, possuir propriedades diuréticas $(76,6 \%)$ e favorecer o emagrecimento (41,7\%). Em estudo (Jotz et al., 2006) realizado para comparar a histologia do trato aerodigestivo de ratos submetidos ao consumo de erva-mate (Ilex paraguariensis), observou-se que o consumo do chimarrão favorece o emagrecimento.

A percepção dos pesquisados como "pouco benéfico" teve maior ocorrência nas variáveis: estimulante da atividade física e mental, para o coração e sistema nervoso. E, como "nenhum benefício" as variáveis: diminuição de estados depressivos, regulador das funções sexuais e antioxidantes. Nesse sentido, Funck (2008) salienta que a erva-mate pode ser recomendada para artrite, dor de cabeça, constipação, reumatismo, estimulante, hemorroidas, obesidade, fadiga, retenção de líquido, hipertensão, digestão lenta e desordens hepáticas. O chimarrão exerce função benéfica sobre o corpo humano, dissipando a fadiga, reduzindo retenção de líquidos, estimulando o sistema nervoso, reduzindo hipertensão, facilitando a digestão e proporcionando sensação de bem-estar além de ser um alimento natural (BASTOS \& TORRES, 2003).

A erva-mate é uma planta com efeitos benéficos à saúde, principalmente à atividade antioxidante e protetora em relação a processos degenerativos (doenças cardiovasculares e danos ao DNA) (MACHADO et al., 2007).

Quanto às concepções dos indivíduos que integraram a pesquisa referente aos efeitos maléficos do chimarrão (efeitos da erva-mate e da temperatura), incluindo sintomas e patologias (Tabela 3), observou-se que praticamente a metade deles o considera "pouco prejudicial". Existem evidências de que o consumo de chimarrão é prejudicial, relacionado à alta incidência de câncer nas regiões sul do Brasil, Uruguai e Argentina (CANTERLE, 2005). As infusões com erva-mate à temperatura ambien-

Tabela 2. Concepção dos pesquisados quanto aos efeitos benéficos do chimarrão

\begin{tabular}{l|c|c|c|c}
\hline Benefícios do chimarrão & $\begin{array}{c}\text { Muito } \\
\text { Benéfico }\end{array}$ & $\begin{array}{c}\text { Pouco } \\
\text { Benéfico }\end{array}$ & $\begin{array}{c}\text { Nenhum } \\
\text { Benefício }\end{array}$ & Indiferente \\
\cline { 2 - 5 } & $\mathrm{n}(\%)$ & $\mathrm{n}(\%)$ & $\mathrm{n}(\%)$ & $\mathrm{n}(\%)$ \\
\hline $\begin{array}{l}\text { Estimulante da atividade física } \\
\text { e mental* }\end{array}$ & $55(27,0)$ & $105(51,5)$ & $30(14,7)$ & $14(6,9)$ \\
Estimula o coração e sistema & $31(15,3)$ & $96(47,5)$ & $43(21,3)$ & $32(15,8)$ \\
nervoso*** & & & & \\
Facilita a digestão* & $133(65,2)$ & $35(17,2)$ & $21(10,3)$ & $15(7,4)$ \\
Favorece a evacuação (fezes) & $51(24,9)$ & $22(10,7)$ & $36(17,6)$ & $96(46,8)$ \\
Eliminar estados depressivos & $51(25,1)$ & $41(20,2)$ & $76(37,4)$ & $35(17,2)$ \\
(ansiedade)** & & & & \\
Promove sensação de bem- & $72(35,6)$ & $41(20,3)$ & $67(33,2)$ & $22(10,9)$ \\
estar e vigor** & & & \\
Estimula a memória** & $24(11,8)$ & $23(11,3)$ & $61(30,0)$ & $95(46,8)$ \\
$\begin{array}{l}\text { Diurético } \\
\text { Favorece o emagrecimento* }\end{array}$ & $157(76,6)$ & $35(17,1)$ & $9(4,4)$ & $4(2,0)$ \\
Regula as funções sexuais & $12(5,9)$ & $15(7,3)$ & $127(62,0)$ & $51(24,9)$ \\
Antioxidante: combate os & $17(8,4)$ & $27(13,3)$ & $107(52,7)$ & $52(25,6)$ \\
radicais livres** & & & & \\
Diminui o colesterol no & $28(13,7)$ & $37(18,0)$ & $59(28,8)$ & $81(39,5)$ \\
sangue & & & & \\
\hline
\end{tabular}

\% válida: * um entrevistado não respondeu; ** dois entrevistados não responderam; ${ }^{* * *}$ três entrevistados não responderam.

Fonte: Dados da pesquisa - 2008 . 
Tabela 3. Concepções referentes aos efeitos maléficos do consumo de chimarrão

\begin{tabular}{l|c|c|c|c}
\hline Malefícios do chimarrão & $\begin{array}{c}\text { Muito } \\
\text { Prejudicial }\end{array}$ & $\begin{array}{c}\text { Pouco } \\
\text { Prejudicial }\end{array}$ & $\begin{array}{c}\text { Nada } \\
\text { Prejudicial }\end{array}$ & Indiferente \\
\cline { 2 - 5 } & $\mathrm{n}(\%)$ & $\mathrm{n}(\%)$ & $\mathrm{n}(\%)$ & $\mathrm{n}(\%)$ \\
\hline $\begin{array}{l}\text { Lesões internas na boca e } \\
\text { na garganta** }\end{array}$ & $26(12,8)$ & $111(54,7)$ & $55(27,1)$ & $11(5,4)$ \\
$\begin{array}{l}\text { Formação de tumores } \\
\text { aerodigestivos }\end{array}$ & $27(13,2)$ & $107(52,2)$ & $57(27,8)$ & $14(6,8)$ \\
Câncer na garganta & $25(12,2)$ & $107(52,2)$ & $63(30,7)$ & $10(4,9)$ \\
Perda parcial do paladar* & $11(5,4)$ & $111(54,4)$ & $69(33,8)$ & $13(6,4)$ \\
Insônia & $27(13,2)$ & $102(49,8)$ & $70(34,1)$ & $6(2,9)$ \\
Agitação & $10(4,9)$ & $111(54,1)$ & $75(36,6)$ & $9(4,4)$ \\
Palpitação & $6(2,9)$ & $99(48,3)$ & $81(39,5)$ & $19(9,3)$ \\
Irritabilidade & $3(1,5)$ & $99(48,3)$ & $84(41,0)$ & $19(9,3)$ \\
\hline
\end{tabular}

\% válida: * um entrevistado não respondeu; ${ }^{* *}$ dois entrevistados não responderam.

Fonte: Dados da pesquisa - 2008.

te, administrado em ratos por 5 meses, aumentaram as alterações no trato aerodigestivo em relação aos ratos controle (que ingeriram somente água) (Jotz et al., 2006).

Na Tabela 4, são apresentados os dados referentes às concepções dos pesquisados quanto às simbologias associadas ao consumo do chimarrão. Um símbolo por ser repleto de significados, estabelece um reflexo do imaginário, revelando ideias e valores de um grupo social (ALBECHE, 1996). Dessa forma, o chimarrão constitui-se no principal símbolo do Rio Grande do Sul, ou seja, na tradição representa a questão cultural, a preservação da própria identidade, hospitalidade e da amizade do povo gaúcho (PEREIRA et al., 2004). É comum às culturas tradicionalistas a transmissão de

Tabela 4. Concepções dos pesquisados referente às simbologias associadas ao consumo do chimarrão

\begin{tabular}{l|c|c}
\hline \multirow{2}{*}{ Símbolo } & Sim & Não \\
\cline { 2 - 3 } & $\mathrm{n}(\%)$ & $\mathrm{n}(\%)$ \\
\hline Integração* & $188(92,2)$ & $16(7,8)$ \\
Herança dos antepassados & $185(90,2)$ & $20(9,8)$ \\
Hospitalidade & $196(95,6)$ & $9(4,4)$ \\
Família & $200(97,6)$ & $5(2,4)$ \\
Amizade* & $202(99,0)$ & $2(1,0)$ \\
Afirmação de personalidade gaúcha** & $190(93,6)$ & $13(6,4)$ \\
Solidariedade & $99(48,3)$ & $106(51,7)$ \\
Respeito & $175(85,4)$ & $30(14,6)$ \\
Cumplicidade & $102(49,8)$ & $103(50,2)$ \\
Democracia* & $113(55,4)$ & $91(44,6)$ \\
Descontração & $188(91,7)$ & $16(7,8)$ \\
Fraternidade & $175(85,4)$ & $29(14,1)$ \\
\hline
\end{tabular}

\% válida: ${ }^{*}$ um entrevistado não respondeu; ${ }^{* *}$ dois entrevistados não responderam. Fonte: Dados da pesquisa - 2008. 
Tabela 5. Temperatura do chimarrão

\begin{tabular}{lcc}
\hline Característica & $\mathrm{N}$ & \\
\hline Temperatura & & \\
Garrafa Térmica & & \\
Menos de 60 & 3 & 1,4 \\
$60 \mid---70$ & 22 & 10,7 \\
$70 \mid---80$ & 121 & 59,0 \\
80 |--- 90 & 59 & 28,9 \\
Temperatura Cuia & & \\
Menos de 60 & 30 & 14,7 \\
$60 \mid---65$ & 49 & 23,9 \\
$65 \mid---70$ & 93 & 45,3 \\
$70 \mid---75$ & 33 & 16,1 \\
\hline
\end{tabular}

Fonte: Dados da pesquisa - 2008 .

seus hábitos alimentares às novas gerações por meio de ensinamento informal adquirido nas refeições com familiares e amigos (PINEYRUA, 2006).

Foi constatado que a grande maioria (mais de $85 \%$ ) o considera símbolo de: integração, herança dos antepassados, hospitalidade, família, amizade, afirmação de personalidade gaúcha, respeito, descontração e fraternidade. O chimarrão é uma tradição alimentar para os gaúchos (BRADALISE, 2002) e o mesmo é partilhado e bebido por todos em uma mesma cuia, gerando sentimento de hospitalidade e amizade, não podendo ser considerado uma bebida popular (BOGUSZEWSKI, 2007).

Visando complementar as concepções dos pesquisados referentes ao uso do chimarrão aliadas a literatura pesquisada verificou-se também a temperatura da água do mesmo, tanto antes do consumo, isto é, na garrafa térmica, quanto no momento do consumo na cuia. Observou-se que a média da temperatura da água da térmica foi de $75,78^{\circ} \mathrm{C}$ com desvio padrão de $5,95^{\circ} \mathrm{C}$, perfazendo um coeficiente de variação de 7,85\%.
Quando observada a temperatura média da água da cuia, esta foi de $64,76^{\circ} \mathrm{C}$ com desvio padrão de $4,79^{\circ} \mathrm{C}$, produzindo um coeficiente de variação de 7,40\%. Alguns resultados de pesquisas (VICTORA et al., 1987; BARROS et al., 2000; CASTELLSAGUÉ et al., 2000; DE STEFANI et al., 2003; SILVA, 2008; FUNCK, 2008) mostram que a ingestão de bebidas quentes, como o chimarrão, à temperatura superior a $60^{\circ} \mathrm{C}$, juntamente com a quantidade ingeridas são considerados fatores de risco do câncer de esôfago.

Em relação aos dados contidos na Tabela 5, a temperatura da garrafa térmica para $87,81 \%$ dos pesquisados é igual ou superior a $70^{\circ} \mathrm{C}$. Quando observada a temperatura na cuia, constata-se que em $61,4 \%$ delas a temperatura é de $65^{\circ} \mathrm{C}$ ou mais. Esse resultado é preocupante, tanto se observadas às médias e sua variabilidade quanto à frequência dos intervalos, pelo fato da prevalência da alta temperatura. O principal fator de risco para o crescimento da incidência do câncer de esôfago pode ser a temperatura elevada de ingestão de bebidas e alimentos,

Tabela 6. Percepções do usuário referentes à temperatura da água na cuia com a temperatura aferida

\begin{tabular}{lccc}
\hline & \multicolumn{3}{c}{ Temperatura Cuia em ${ }^{\circ} \mathrm{C}$} \\
\cline { 2 - 4 } & $\leq 60$ & $>60$ & Total \\
Percepções & $\mathrm{N}(\%)$ & $\mathrm{N}(\%)$ & $\mathrm{N}(\%)$ \\
\hline Morno & $14(7,1)$ & $30(15,2)$ & $44(22,2)$ \\
Quente & $27(13,6)$ & $124(62,6)$ & $151(76,3)$ \\
Muito quente & $1(0,5)$ & $2(1,0)$ & $3(1,5)$ \\
\hline Total & $42(21,2)$ & $156(78,8)$ & $198(100)$ \\
\hline
\end{tabular}

* Sete entrevistados não responderam.

Fonte: Dados da pesquisa - 2008 
que causaria lesões termais crônicas na mucosa esofágica (VICTORIA et al. 1990).

Quando relacionadas à temperatura da cuia e as percepções referentes à temperatura da água (Tabela 6), verifica-se que $15,2 \%$ dos entrevistados têm a percepção que a água está morna e 62,6\% a consideram apenas quente na temperatura da cuia aferida, que é de mais de $60{ }^{\circ} \mathrm{C}$. As temperaturas superiores a $60{ }^{\circ} \mathrm{C}$ podem ser consideradas um fator de risco (BARROS et al., 2000). Pesquisas (LORIA et al., 2009) salientam que o consumo de bebidas quentes, aliado a cigarros e bebidas alcoólicas podem causar maior incidência de diferentes tipos de câncer.

Alguns fatores capazes de auxiliar o processo carcinogênico no esôfago, pela ingestão de bebidas quentes, são o aumento de processos inflamatórios e a produção de substâncias mutagênicas e/ou carcinogênicas, como os hidrocarbonetos policíclicos aromáticos, produzidos durante a secagem e processamento da erva-mate (PUTZ et al., 2002; ZUIN et al., 2005; KAMANGAR et al., 2008; CAMARGO \& TOLEDO, 2009).

A falta de informação dos usuários sobre os riscos à saúde quando do consumo de chimarrão em temperaturas altas é evidenciado nessa pesquisa. As informações são importantes ao homem para sua sobrevivência sendo fonte de integração do seu meio com a sociedade (ALBUQUERQUE et al., 2009).

A análise dos resultados da temperatura do chimarrão consumido é merecedora de ações dos profissionais da saúde e áreas afins, incluindo pesquisadores e estudantes no sentido de promover a saúde e prevenir danos à mesma.

\section{4 conclusões}

O chimarrão é conhecido como uma forma de eternizar as tradições regionais e principalmente familiares, com a transmissão dos conhecimentos entre gerações. O estudo confirma essa concepção e assim caracteriza a população quanto ao hábito e efeitos do uso do chimarrão, entretanto demonstra a falta de conhecimento dos entrevistados sobre os possíveis efeitos maléficos aos consumidores do chimarrão.

Dessa forma, pode-se afirmar que os indivíduos pesquisados utilizam a referida bebida em altas quantidades e em temperatura superior a $60^{\circ} \mathrm{C}$, o que pode se constituir em um fator contribuinte para câncer de esôfago.

Os resultados obtidos com essa pesquisa são merecedores de reflexões, discussões e ações dos profissionais da saúde e áreas afins, incluindo a mobilização do setor público na viabilização de estratégias no sentido de reduzir a falta de informação quanto à possibilidade de minimizar riscos à saúde dos consumidores do chimarrão.

\section{Referências}

ALBECHE, D. L. Imagens do gaúcho: história e mitificação. Porto Alegre: EDIPUCRS, 1996.

ALBUQUERQUE, E. M.; OLIVEIRA, D. F. S.; RAMALHO, F. A. Necessidades e usos de informação: um estudo com os médicos das Unidades de Saúde da Família, do Distrito Sanitário V, da cidade de João Pessoa - PB. Informação \& Sociedade: Estudos, v. 19, n. 2, p. 119-134, 2009.

ALVES, R. J. V. et al. Erva-mate (Ilex paraguariensis) como agente etiológico de neoplasia de língua. Revista da AMRIGS, Porto Alegre, v. 1, n. 51, p. 7-11, 2007.

BARBETTA A. P. Estatística aplicada às ciências sociais. 7a ed. Florianópolis (SC): UFSC, 2007.

BARROS, S. G. S. et al. Mate chimarrão é consumido em alta temperatura por população sob risco para o carcinoma epidermóide de esôfago. Arquivos de Gastroenterologia, v. 37, n. 1, p. 25-30, 2000.

BASTOS, D. H. M.; TORRES, E. A. F. S. Bebidas a base de erva-mate (Ilex paraguariensis) e saúde pública. Journal of the Brazilian Society of Food and Nutrition, v. 26, p. 77-89, 2003.

BOGUSZEWSKI, J. H. Uma história cultural da ervamate: o alimento e suas representações. Curitiba: UFP, 2007, 109 p. Dissertação (Mestrado em História) -Universidade Federal do Paraná, 2007.

BRANDALISE, R. Gaúchos e gauchos: um pampa, duas nações. In: INTERCOM -Congresso Anual em Ciências da Comunicação, XXV. 2002, Salvador. Anais... Salvador, 2002.

CAMARGO, M. C. R. \& TOLEDO, M. C. T. Chá mate e café como fontes de hidrocarbonetos polihidroxi aromáticos (HPAs) na dieta da população de campinas. Ciência e Tecnologia de Alimentos, v.19, n.1. p. 49-53, 2002.

CANTERLE, L. P. Erva-mate e antioxidante. Santa Maria: UFSM, 2005. 99 p. Dissertação (Mestrado em Ciências e Tecnologia dos Alimentos) Universidade Federal de Santa Maria, 2005.

CASTELLSAGUÉ, X. et al. Influence of mate drinking, hot beverages and diet on esophageal cancer risk in South America. International Journal of Cancer, v. 88, p. 658-664, 2000. 
CRADDOK,V. M., Etiology of esophageal cancer: some operative factors. European Journal of Cancer Prevention, v. 1, p. 89-103, 1992.

DAY, N. E. \& VARGHESE, C. Esophageal cancer. Cancer Survival, v. 20, p. 43-54, 1994.

DE STEFANI, E. et al. Food groups and risk of squamous cell carcinoma of the oesophagus: a case-control study in Uruguay. British Journal of Cancer, v. 89, p. 1209-1214, 2003.

ERNST, E. Toxic heavy metals and undeclared drugs in Asian herbal medicines. Trends Pharmacological Science, v. 23, p. 136-139, 2002.

FREITAS, L. F. R. \& SILVEIRA, R. M. H. A Figura do Gaúcho e a Identidade Cultural Latino-Americana. Educação, n. 2, v. 53, p. 263-281, 2004.

FUNCK, A. Efeitos anti-obesidade da erva-mate (Ilex paraguariensis) em camundongos. Bragança Paulista: USF, 2008. 55 p. Dissertação (Mestrado em Ciências da Saúde) - Universidade São Francisco, 2008.

GAMMON, M. D., SCHONBERG, J. B., AHSAN, H. Tabacco alcohol, and socio economic status and adenocarcinomas of the esophagus and gastric cardia. Journal of the National Cancer Institute, v. 89, p. 1277-1284, 1997.

IBGE. Instituto Brasileiro de Geografia e Estatística. Disponível em: http://www.ibge.gov.br/home/ mapa_site/mapa_site.php\#populacao.

Acesso em: 12 Set 2010.

Jotz, G. P. et al. Estudo Experimental da Erva Mate (Ílex Paraguariensis) como Agente Etiológico de Neoplasia do Trato Aéro-digestivo. Arquivo Internacional Otorrinolaringologia, n. 4, v. 10, p. 306-311, 2006.

KAMANGAR F. et al. High levels of carcinogenic polycyclic aromatic hydrocarbons in mate drinks. Cancer Epidemiology, Biomarkers \& Prevention, v. 17, p. 1262-1268, 2008.

LORIA D, BARRIOS E, ZANETTI R. Cancer and yerba mate consumption: a review of possible associations. Rev Panam Salud Publica., v. 25, n. 6, p. $530-539,2009$.

MACHADO, C. C. B. et al. Determinação do perfil de compostos voláteis e avaliação do sabor e aroma de bebidas produzidas a partir da erva-mate (Ilex paraguariensis). Química Nova, v. 30, n. 3, p. 513518, 2007.

MEDRADO, M. J. S. \& MOSELE, S. H. O Futuro da investigação Ciêntífica em erva-mate. Colombo: Embrapa Florestal, 2004, 64 p. (Documento, 92)

Michelin, R. L. A construção das idéias de herança cultural, etnicidade e identidade na arena turística do roteiro cultural Caminhos de Pedra - RS. In: Seminário da Associação Brasileira de Pesquisa e Pós-Graduação em Turismo UAM, IV.São Paulo. Anais... São Paulo, 27 a 28 de agosto de 2007.

PEREIRA, A. L. et al. Os símbolos da cultura gaúcha e sua apropriação pela publicidade. In: CONFERENNCIA BRASILEIRA DE FOLKCOMUNICAÇÃO, 7ª . Lajeado. Anais... Lageado, 2004, p. 1-18.

PINEYRUA, D. G. F. Regionalismo Alimentar: identificação de grupos de consumidores que valorizam o prazer e as tradições alimentares. Mato Grosso do Sul: UFMS, 2006. 117 p. Dissertação (Mestrado em Economia e Administração) Universidade Federal do Mato Grosso do Sul, 2006.

PUTZ, A. et al. TP53 Mutation Pattern of Esophageal Squamous Cell Carcinomas in a High Risk Area (Southern Brazil): Role of Life Style Factors. International Journal of Cancer, v. 98, p. 99-105, 2002.

ROLON, P. A. et al. Hot and cold mate drinking and esophageal cancer in Paraguay. Cancer Epidemiology, Biomarkers \& Prevention, v. 4, n. 6, p. 595-605, 1995.

Schneider, A. S.; Schemes, C. E.; Araújo, D. C. O consumidor de moda no Rio Grande do Sul: características e percepções. Moda palavra e-periódico, v. 2, n. 3, p. 13-34, 2009.

SEWRAM, V. et al. Mate consumption and the risk of squamous cell esophageal cancer in Uruguay. Cancer Epidemiology, Biomarkers \& Prevention, v. 12, n. 6, p. 508-513, 2003.

SILVA, J. F. Efeitos da temperatura e do mate (Ilex paraguariensis) sobre o processo de carcinogênese de esôfago em ratos wistar machos. Botucatu, UNESP, 2008. 67p. Dissertação (Mestrado em Biologia Geral e Aplicada). Universidade Estadual de São Paulo, 2008.

VICTORA, C. G. et al. Hot beverages and oesophageal cancer in southern Brazil: a case-control study. 
International Journal of Cancer, v.39, p. 710-716, 1987.

VICTORA C. G. et al. Patterns of mate drinking in a Brazilian city. Cancer Research, v. 50, p. 7112-7115, 1990.

ZUIN, V. G. et al. Stir bar sorptive extraction and high-performance liquid chromatographyfluorescence detection for the determination of polycyclic aromatic hydrocarbons in Mate teas. Journal of Chromatography A, v. 1091, p. 2-10, 2005. 